5 Authors: Charlotte Hall ${ }^{1, \dagger}$, Joanna Milward ${ }^{1, \dagger, *}$, Cristina Spoiala ${ }^{1}$, Jaskiran Kaur Bhogal ${ }^{1}$,

$9 \quad{ }^{\dagger}$ Indicates joint first author. ${ }^{\#}$ Indicates joint last author.

\section{The mental health of staff working on Intensive Care Units over the COVID-19 winter surge of 2020 in England: a cross sectional survey.}

\author{
Word count: 3561
}

*Corresponding author: Joanna Milward. Email: Joanna.Milward@phe.gov.uk

1: Behavioural Science and Insights Unit, UK Health Security Agency, Salisbury, UK.

2: Institute of Health Informatics, University College London, UK.

3: Department of Computer Science, University College London, London, UK.

4: King's College Hospital, London, UK.

5: National Institute for Health and Care Excellence, London, UK.

6: Department of Anaesthesia, Guy's \& St Thomas' NHS Trust, London, UK.

7: Department of Anaesthesia, Mersey Deanery, Liverpool, UK

8: Department of Science, Technology, Engineering and Public Policy (STEaPP), University College London, London, UK,

9: Department of Anaesthesia, University College London Hospital, London, UK.

10: King's Centre for Military Health Research, Institute of Psychology, Psychiatry and Neuroscience, King's College London, London, UK

11: Health Protection Research Unit, Institute of Psychology, Psychiatry and Neuroscience, King's College London, London, UK 
medRxiv preprint doi: https://doi.org/10.1101/2022.01.13.22269151; this version posted January 13, 2022. The copyright holder for this preprint (which was not certified by peer review) is the author/funder, who has granted medRxiv a license to display the preprint in perpetuity. It is made available under a CC-BY-ND 4.0 International license.

27

28 Keywords: COVID-19, Intensive Care, Mental Health, PTSD, Presenteeism, Healthcare

29 worker, Functional impairment.

30

31

32

33

34

35

36

37

38

39

40

41

42

43

44

45

46

47

48

49

50

51 


\section{Abstract}

53 Background: The COVID-19 pandemic generated a surge of critically ill patients greater

54 than the NHS' capacity. Additionally, there have been multiple well-documented impacts

55 associated with the national COVID-19 pandemic surge on ICU workers, including an

56 increased prevalence of mental health disorders on a scale potentially sufficient to impair

57 high-quality care delivery.

58 Aim: To identify prevalence of probable mental health disorders and functional impairment.

59 As well as establish demographic and professional predictors of probable mental health

60 disorders and functional impairment in ICU staff between November 2020 to April 2021.

61 Methods: English ICU staff were surveyed before, during and after the winter 2020/2021

62 surge using a survey which comprised of validated measures of mental health.

63 Results: 6080 surveys were completed, by nurses (57.5\%), doctors (27.9\%), and other

64 healthcare staff (14.5\%). Reporting probable mental health disorders increased from 51\%

65 (prior to), to 64\% (during) and then dropped to $46 \%$ (after). Younger, less experienced and

66 nursing staff were most likely to report probable mental health disorders. Additionally, during

67 and after the winter, over $50 \%$ of participants met threshold criteria for functional

68 impairment. Staff who reported probable post-traumatic stress disorder, anxiety or depression

69 were more likely to meet threshold criteria for functional impairment.

70 Conclusions: The winter of 2020/2021 was associated with an increase in poor mental health

71 outcomes and functional impairment during a period of peak caseload. These effects are

72 likely to impact on patient care outcomes and the longer-term resilience of the healthcare

73 workforce. 


\section{Introduction}

82 Psychological distress has increased in the general population over the course of the COVID-

8319 pandemic $^{1}$ with key workers reporting higher rates of probable mental health disorders

84 than the general population. ${ }^{2}$ Healthcare workers, particularly those working on the frontline,

85 have experienced high rates of mental health challenges such as depression, anxiety, stress,

86 and burnout $\mathrm{t}^{3-7}$. Furthermore, health and social care workers were already reporting high

87 levels of pre-existing mental health disorders that may have increased their risk of

88 experiencing mental health during a public health emergency. ${ }^{4}$

During the pandemic, staff working on intensive care units (ICUs), including doctors, nurses, and other healthcare professionals, have arguably been the most directly impacted by the surge in critically ill COVID-19 patients. Nurses appear to have been particularly exposed and have reported higher rates of symptoms consistent with common mental disorders and post-traumatic stress disorder (PTSD) compared to other ICU staff. ${ }^{8}$ During the pandemic, ICU staff have faced a constellation of specific stressors. These include the perceived risk to their own health from exposure to COVID-19, very high mortality rates among the patients in their care, ${ }^{9}$ reduced staffing ratios, shortages of personal protective equipment and the need to work beyond their level of seniority. ${ }^{10}$

Poor mental health of ICU staff has the potential to impact the quality and safety of patient care. The phenomenon of presenteeism, in which staff continue to work while functionally impaired by the state of their mental health, may lead to an increased risk of errors and poorer performance, which in turn may impact the quality and safety of patient care. ${ }^{11,12}$

With COVID-19, and the backlog of care resulting from the pandemic, exerting ongoing pressures on ICU resources, it is important to understand how the mental health of ICU workers has been impacted. This is essential in the identification of risk factors in this population, to help ensure that appropriate support is made available for all, ${ }^{13}$ and to inform future pandemic planning.

107 Building on the initial ICU mental health survey conducted by Greenberg et al., ${ }^{8}$ which found substantial rates of probable mental health disorders in ICU staff, this study analysed data from three subsequent timepoints of the survey corresponding to before, during and after the peak of the COVID-19 winter 2020/2021 surge in England, to explore the impact of this 
medRxiv preprint doi: https://doi.org/10.1101/2022.01.13.22269151; this version posted January 13, 2022. The copyright holder for this preprint (which was not certified by peer review) is the author/funder, who has granted medRxiv a license to display the preprint in perpetuity. It is made available under a CC-BY-ND 4.0 International license .

112 Therefore, the current study aimed to: describe the prevalence of five mental health

113 outcomes: probable depression, probable PTSD, probable general anxiety disorder, and

114 problem drinking, in ICU staff over the winter 2020/2021 surge in England; explore

115 demographic and professional predictors of poorer mental health outcomes in ICU staff over

116 the 2020/2021 winter surge in England; describe the prevalence of functional impairment in

117 ICU staff over the 2020/2021 winter surge in England; and, explore demographic and

118 professional predictors of functional impairment in ICU staff over the 2020/2021 winter

119 surge in England.

120

121

122

123

124

125

126

127

128

129

130

131

132

133

134

135

136 


\section{Study setting}

140 An online cross-sectional survey was designed and run in 56 English ICUs, which

141 experienced a surge in adult patients, above their formally commissioned baseline. Collection

142 occurred across three time points: before the peak $-19^{\text {th }}$ November to $17^{\text {th }}$ December 2020;

143 during the peak $-26^{\text {th }}$ January $-17^{\text {th }}$ February 2021 ; and after the peak $-14^{\text {th }}$ April $-24^{\text {th }}$ May

144 2021. These data collection points were part of an ongoing service evaluation of ICU staff's mental health which commenced in June $2020{ }^{8}$

This study was approved by the Psychiatry, Nursing and Midwifery Research Ethics

147 Subcommittee, King's College London reference number: MOD-20/21-18162.

The 56 NHS hospitals which provided data comprised of District General Hospitals,

Teaching Hospitals and Quaternary Paediatric Hospitals. The selection process reflected hospitals utilising surge capacity and hospitals receiving or making use of interhospital transfers as part of mutual aid support between neighbouring units. Where possible, data for hospital baseline ICU bed number (as declared in 2020, immediately prior to the pandemic) and actual maximum occupancy during COVID-19 was collected. All surveyed units exceeded $100 \%$ of their baseline ICU capacity during the winter 2020/2021 surge.

\section{Survey design}

Data were collected via an anonymised web-based survey, designed to be completed in less than 5 minutes, comprising validated questionnaires assessing mental health status and psychological well-being. Participants were aware that their participation was voluntary, their data would be anonymised, they were free to stop at any point during the completion of the study and any incomplete surveys would be discarded. The Lime Survey tool (https://www.limesurvey.org/) was used to build the survey and hosted on a dedicated secure university server.

\section{Survey distribution}

164 Circulation and completion of the survey was encouraged through engagement with clinical

165 leads in each of the intensive care units. The survey was distributed through departmental 166 email and messaging groups. All staff working in ICUs (doctors, nurses, and other healthcare professionals) were eligible to take part. Due to the recruitment method, the size of the 
sample was determined by the participants who chose to complete the survey. Individual respondents could not be followed across timepoints as the survey was anonymous in order to reduce barriers to reporting. ${ }^{15,16}$ No participant data were excluded. Figure 1 displays a participant flow chart.

\section{[INSERT FIGURE 1 HERE]}

\section{Collected variables and outcome definitions}

Demographic data collected included age, gender, job role and seniority. Doctors who were graded FY 1-2, ST 3-4, ST 5-6, ST 6-7 were classed as junior staff (staff still in training) and consultant and senior associate specialists as senior staff. Nurses in Band 5 (i.e. those newly qualified or staff nurses) or Band 6 (i.e. those who are nursing specialists or senior nurses) were classed as junior, with Band 7 (i.e. those who are advanced nurses or nurse practitioners) or higher (e.g. Matrons) classed as seniors.

The following measures, for which binary outcomes were set following cut-off scores to indicate a case, were used; the 9-item Patient Health Questionnaire (PHQ-9) with a score of $>9$ indicating probable moderate depression and $>19$ probable severe depression; ${ }^{17}$ the 6 -item Post-Traumatic Stress Disorder checklist (PCL-6) with a score of $>17$ indicating the presence of probable PTSD $;{ }^{18}$ AUDIT-C with a score of $>7$ indicating problem drinking; ${ }^{19}$ the 7 -item Generalized Anxiety Disorder (GAD) scale with a score $>9$ indicating a probable moderate anxiety disorder and $>15$ indicating probable severe anxiety disorder. ${ }^{20}$ The primary variable was defined, any mental disorder (AMD), which referred to those meeting the threshold criteria for at least one of the following probable mental disorders: moderate or severe anxiety, moderate or severe depression, problem drinking, or PTSD.

The Work and Social Adjustment Scale (WSAS) was added to the survey during the surge, therefore data is only available for the timepoints during and after the peak. The scale is based on how much an individual's ability to carry out day-to-day tasks is impacted by an identified problem in their lives (e.g. "Because of the way Ifeel my ability to work is impaired'), and consists of 5 items answered on an 8-point Likert scale. A score of $>20$ indicated severe psychopathology-related functional impairment and a score of $>10$ indicated moderate functional impairment. ${ }^{14}$

\section{Statistics}


medRxiv preprint doi: https://doi.org/10.1101/2022.01.13.22269151; this version posted January 13, 2022. The copyright holder for this preprint (which was not certified by peer review) is the author/funder, who has granted medRxiv a license to display the preprint in perpetuity.

It is made available under a CC-BY-ND 4.0 International license .

199 Using SPSS V27, descriptive statistics were plotted using counts and percentages for all 200 mental health outcomes across the entire sample. The various measures of psychological 201 distress were highly correlated, so one multivariable logistic regression was carried out using 202 AMD, with demographic (i.e. gender, age) and professional variables (i.e. role, seniority) as 203 predictors. A second multivariable logistic regression was carried out for Work and Social 204 Adjustment Scale, with all probable mental health disorders, demographic and professional 205 variables entered as predictors. Because of the small sample size of other healthcare 206 professionals, only doctors and nurses were included in the logistic regressions. Comparator 207 groups were chosen based on expected impact (e.g. junior staff would be impacted more senior staff, so senior staff became the reference category). Additionally, senior nurses were compared to all others (junior nurses and all doctors), and senior doctors were compared to all others (junior doctors and all nurses), as we expected that the effect of seniority might be different across the professions. AMD and WSAS were visually compared across timepoints using forest plots with odds ratios and confidence intervals shown. Inferential statistics comparing across waves were not possible due to lack of independence of observations: as the survey was completed anonymously, we could not match responses in different waves that may have been from the same individuals. 


\section{Results}

\section{Demographics}

230 Table 1 displays the characteristics of the sample used within the current study. Across all

231 three timepoints, most respondents were female, and the modal age group was 30-44 years

232 old. Nurses comprised over $50 \%$ of the sample at all timepoints; they were mainly junior

233 (Band 6 or below) and were regular ICU, rather than redeployed, staff. Doctors constituted

234 around $30 \%$ of the sample; the majority were anaesthetists and of a senior level (i.e. Senior

235 Associate Specialist or Consultant).

\section{[INSERT TABLE 1 HERE]}

\section{Mental Health Measures}

\section{Prevalence}

240 Figure 2 shows the percentage of ICU staff meeting the threshold criteria for all tested mental

241 health measures. A clear pattern was observed across the timepoints. The prevalence of all

242 tested mental disorders increased between before and during the peak (e.g. AMD 51.3\%

243 [47.8-54.8] vs 64.6 [62.8-66.4]), and then decreased after the peak (e.g. AMD 45.5 [43.6-

244 47.5].

245 Probable moderate depression was the most common across all time points (before: $40.5 \%$

246 [37.1-44.0]; during 52.3\% [50.4-54.2]; after: 33.9\% [32.0-35.8]), followed by probable PTSD

247 (before: 31.3\% [28.1-34.6]; during 46.5\% [44.6-48.4]; after: 28.8\% [27.0-30.6]), and

248 moderate anxiety (before: $29.7 \%$ [26.5-33.0]; during 43.7\% [41.8-45.5]; after: $25.7 \%$ [24.0-

$24927.5])$.

\section{[INSERT FIGURE 2 HERE]}

Adjusted outcomes

253 A multivariable logistic regression was performed to ascertain the association of age, gender, 254 job role, and seniority with the likelihood that participants experienced AMD at each of the 255 three timepoints. Results were relatively consistent across time. Figure 3 displays a forest plot

256 of effect size and confidence intervals to allow visual comparison across timepoints. Older 
medRxiv preprint doi: https://doi.org/10.1101/2022.01.13.22269151; this version posted January 13, 2022. The copyright holder for this preprint (which was not certified by peer review) is the author/funder, who has granted medRxiv a license to display the preprint in perpetuity.

It is made available under a CC-BY-ND 4.0 International license .

257

258

259

260

261

262

263

264

265

266

267

268

269

270

271

272

273

274

275

276

277

278

279

280

281

282

283

284

285

286

staff (30+ years old) showed lower rates of AMD at all timepoints, with this result being statistically significantly for some age groups during and after the peak. Nurses were more likely than doctors to have experienced AMD, although this was only statistically significantly during the peak. Junior nurses were more likely than senior nurses or any doctors to have experienced AMD and this was significant during and after the peak. There were no statistically significant differences by gender or doctor seniority at any timepoint.

[INSERT FIGURE 3 HERE]

\section{Functional impairment (Work and Social Adjustment Scale)}

\section{Prevalence}

Functional impairment was more prevalent during the peak in comparison to after. During the peak, 69.1\% [67.4-70.8] of participants met the threshold criteria for functional impairment (consisting of $27.9 \%$ moderate and $41.2 \%$ severe). After the peak, 52.8\% [50.8-54.7] of participants met the threshold criteria for functional impairment (consisting of $27.3 \%$ moderate and $25.5 \%$ severe).

\section{Adjusted outcomes}

A multivariable logistic regression was performed to ascertain the association of age, gender, job role, seniority, and all mental health outcomes, with the likelihood that participants met the threshold criteria for functional impairment at both timepoints. Figure 4 displays a forest plot of effect size and confidence intervals to allow visual comparison across timepoints. Across both timepoints (during and after the peak), those with probable moderate depression (during $\mathrm{OR}=4.7$, after $\mathrm{OR}=4.7$ ), probable moderate anxiety (during $\mathrm{OR}=2.4$, after $\mathrm{OR}=$ 3.3), and probable PTSD (during $\mathrm{OR}=6.4$, after $\mathrm{OR}=4.6$ ) were all more likely to experience functional impairment in comparison to those without. There was no statistically significant relationship with problem drinking. While functional impairment was more prevalent overall during the peak, there was little difference in the likelihood of functional impairment between those with and without AMD $(\mathrm{OR}=0.95)$. After the peak, those respondents with AMD were twice as likely as those without to experience functional impairment. Controlling for mental health outcomes, there were no independent, statistically 
medRxiv preprint doi: https://doi.org/10.1101/2022.01.13.22269151; this version posted January 13, 2022. The copyright holder for this preprint (which was not certified by peer review) is the author/funder, who has granted medRxiv a license to display the preprint in perpetuity.

It is made available under a CC-BY-ND 4.0 International license .

287

288

289

290

291

292

293

294

295

296

297

298

299

300

301

302

303

304

305

306

307

308

309

310

311

312

313

314

315

316

317

significant differences by age, gender, job role, or job seniority (for both doctors and nurses) at any timepoint.

\section{[INSERT FIGURE 4 HERE]}

\section{Discussion}

This study examined the mental health of ICU workers between November 2020 to April 2021, during the winter COVID-19 surge in England. At the peak of the winter COVID-19 patient surge, almost two thirds of ICU staff sampled met the threshold criteria for at least one of the surveyed probable mental health disorders. The likelihood of reporting AMD was particularly high in younger, junior nurses. Over half of sampled ICU staff during and after the winter COVID-19 surge met the threshold criteria for functional impairment, with the likelihood of meeting the threshold criteria for functional impairment being substantially increased by the presence of probable PTSD, anxiety or depression.

High rates of probable mental health problems were expected. These findings align with research indicating an increased rate of probable mental health disorders among frontline healthcare staff, ${ }^{2}$ with particular strain during this unprecedented stressful time. ${ }^{8,9}$ General population studies have shown comparable rates of probable, common mental health problems: using the PHQ-4, Smith and colleagues found comparable case rates and patterns over time in an England population survey, ${ }^{21}$ while Fancourt and colleagues, using the PHQ9 and GAD-7, found probable depression and anxiety to be high, but lower over the comparable period. ${ }^{22}$

Beyond the common mental health disorders, our study includes a self-report measure of PTSD symptoms, the PCL-6. We identified that a sizeable fraction of respondents met or exceeded the threshold for probable PTSD at all three time points. Whilst there are no robust pre-pandemic data from ICU staff against which to compare this finding, we note these rates of probable PTSD are comparable to that seen in British military veterans deployed in a combat role during the war in Afghanistan. ${ }^{23}$

Our finding that younger staff were more at risk of reporting AMD was in keeping with previous literature showing similar findings in the general population where younger adults are more likely to report poor wellbeing. ${ }^{22,24-27}$ However, the risk of reporting AMD was also increased by being a nurse, particularly a junior nurse. This finding matches our previous 
medRxiv preprint doi: https://doi.org/10.1101/2022.01.13.22269151; this version posted January 13, 2022. The copyright holder for this preprint (which was not certified by peer review) is the author/funder, who has granted medRxiv a license to display the preprint in perpetuity.

It is made available under a CC-BY-ND 4.0 International license .

318

319

320

321

322

323

324

325

326

327

328

329

330

331

332

333

334

335

336

study, carried out in June/July 2020, which also concluded that nurses were more at risk than other healthcare professionals working in ICU during the COVID-19 pandemic, ${ }^{8}$ as well as other current research. ${ }^{28,29}$ Studies of emergency services ${ }^{30}$ consistently find that lower grade/ranked staff are more likely to report poorer mental health. This may be because those who remain in lower grades are more vulnerable to develop problems in the first place, possibly due to pre-role life adversity which has also been shown to be linked to worse mental health, ${ }^{31}$ or because they are more likely to be directly exposed to significant trauma at work because of their 'coalface' role. Similar results may be found for lower grade nursing staff who are more likely to be directly interacting with patients, and relatives, than more senior staff. However, this paper is the first to show a relationship between seniority and mental health among ICU staff.

This study is also the first to examine the relationship between mental health and functional impairment in staff working in ICUs during the COVID-19 pandemic. We found that over half of the participants met the threshold criteria for functional impairment both during and after the peak of the winter 2020/2021 COVID-19 surge. This points to a potential association between poorer staff mental health quality of care and patient outcomes. Indeed a prospective, observational, multicentre study of 31 ICUs reported that depression symptoms were an independent risk factor for medical errors, as were organisational factors such as training and workloads. ${ }^{32}$

Although not causally measured in the current study, the hypothesised associations between functional impairment and patient safety outcomes, which this research points towards, are highly concerning, since safety critical, vigilance tasks are a core feature in the delivery of critical care and thus staff working in ICU settings must function at a high level to ensure the safety and quality of patient care. Mental health status was associated with functional impairment, with those experiencing probable moderate depression, moderate anxiety, or probable PTSD, more likely to meet the threshold criteria for functional impairment, although it is noted that the direction of this relationship was not tested in the current study. The conduct of a study in the context of ongoing, severe COVID-19 patient surge presented myriad challenges. We drew on the experience of other, clinical research teams operating in this environment, and adopted a pragmatic approach to study design, opting for an agile, scalable tool which allowed the capture of data which has clear limitations but nevertheless provides unique insight into mental health impacts on staff during a unique period of operational stress in the NHS. We identified the following principal limitations: Firstly, due 
medRxiv preprint doi: https://doi.org/10.1101/2022.01.13.22269151; this version posted January 13, 2022. The copyright holder for this preprint (which was not certified by peer review) is the author/funder, who has granted medRxiv a license to display the preprint in perpetuity.

It is made available under a CC-BY-ND 4.0 International license .

351 to not collecting identifiable data within the surveys (to ensure anonymity), it was not possible to either link cases to allow for longitudinal analysis at the level of individuals, or establish exclusivity between cases, rendering the data collected effectively cross-sectional.

Therefore, time (before, after and during the peak) were not entered together into the statistical analysis. Secondly, we do not have data on the current demographic and professional characteristics of the ICU staff population during the COVID-19 crisis, so we do not know how representative the current study is. Additionally, data on ethnicity was not collected as part of the survey, limiting the generalisability of the findings. Thirdly, the recruitment method leaves open the possibility that those with more severe mental health symptoms might be more - or less - likely to participate, thus leading to bias. Fourthly, this study uses self-report measures which only provide an estimate of prevalence; interviewbased studies are required to establish the true prevalence of those who would meet diagnostic criteria. Lastly, we recognise that the reported confidence intervals within the regression models are relatively large, which suggests imprecision of observed results. However, this is expected as there were only a limited number of participants at each time point and the differences across time points remain consistent within the confidence intervals, meaning useful conclusions can still be drawn from the analysis.

Future research should explore in further detail the casual relationship between mental health in ICU staff, patient care and outcomes. Such research, into ICU staff's mental health and functional impairment, should seek to collect identifiable information to allow cases to be linked over time, for a more nuanced statistical analysis to be carried out. Additionally, the Work and Social Adjustment Scale, to measure functional impairment was added to the survey during the surge thus, future additional survey timepoints would allow for further developed analysis of functional impairment.

Recognising that the pandemic placed extraordinary pressure on the NHS, the results of this paper suggest that employers should ensure that all staff working in ICUs are provided with suitable support and this is especially true for more junior nursing staff. While much has been written about how best to support healthcare staff in the workplace (e.g. ${ }^{33,34}$ ), evidence points to promotion of social cohesion at work and its role in reducing PTSD symptoms, such as in a sample of military personnel, ${ }^{35}$ organisational level approaches to help reduce burnout

381 in medics, ${ }^{36}$ such as changes in schedule and reductions in the intensity of workloads and to ensure that clinical team leaders feel confident to speak to staff about their mental 
medRxiv preprint doi: https://doi.org/10.1101/2022.01.13.22269151; this version posted January 13, 2022. The copyright holder for this preprint (which was not certified by peer review) is the author/funder, who has granted medRxiv a license to display the preprint in perpetuity.

It is made available under a CC-BY-ND 4.0 International license .

384 Whilst the causes of poor mental health and functional impairment in ICU staff during the

385 pandemic are likely to be complex and multifactorial, and determining the causal relationship

386 between them was outside the scope of the current study, it is nevertheless important for

387 healthcare managers to consider strategies to improve the psychological and functional

388 health of their workforce. Delivering high quality care requires functional staff and we

389 suggest that wellbeing initiatives should be seen through the prism of improving patient

390 safety, experience and outcomes and reducing adverse events. In addition to ensuring

391 psychologically healthy workplaces, managers should also take account of the need for

392 strategies such as adequate resourcing and staffing of intensive care units such that

393 individuals reporting high levels of distress can be rested or temporarily rotated away from

394 higher intensity clinical roles. This in turn requires that demand for healthcare services are

395 matched appropriately and realistically with the available supply of staff and resources,

396 although we recognise the exceptional nature of the COVID-19 pandemic made planning and

397 resourcing difficult.

398 Ultimately, whilst noting caveats about sample representativeness, the current study provides

399 evidence that ICU staff experienced poorer mental health over the winter 2020/2021 COVID-

40019 surge with the majority of those surveyed meeting the threshold criteria for poor mental

401 health. Furthermore, this was associated with evidence of high levels of probable functional

402 impairment on a scale that has the potential to negatively impact the safety and quality of

403 patient care. The study also suggests that we should expect staff's mental health to improve if

404 workload intensity decreases. However, there is, correspondingly, a risk of sustained

405 impairment if demand for healthcare in this setting continues to outstrip capacity. Taken

406 together these findings provide a case for the establishment of a coherent and comprehensive

407 recovery strategy, which appropriately matches demand for healthcare with NHS capacity

408 and human resource, with the goal of protecting staff so that they in turn can continue to

409 deliver safe, high quality patient care. It is essential that staff are properly supported by

410 employers who must recognise the association between mental health status and the ability of

411 staff to safely carry out their caring duties.

412 
medRxiv preprint doi: https://doi.org/10.1101/2022.01.13.22269151; this version posted January 13, 2022. The copyright holder for this preprint (which was not certified by peer review) is the author/funder, who has granted medRxiv a license to display the preprint in perpetuity.

It is made available under a CC-BY-ND 4.0 International license.

\section{$416 \quad$ Funding}

417 This study was supported by the National Institute for Health Research Research Unit (NIHR 418 HPRU) in Emergency Preparedness and Response, a partnership between Public Health

419 England, King's College London and the University of East Anglia. The views expressed are 420 those of the author(s) and not necessarily those of the NIHR, Public Health England, the UK

421 Health Security Agency or the Department of Health and Social Care [Grant number:

422 NIHR20008900].

\section{Collaborators}

424 Lindsay Ayres, Emma, Addie, Angharad Williams, Andrew Lynes, Neil Herbert, Clare

425 Chamberlain-Parr, Paula Clements, Peter Hampshire, Maia Graham, Alison Hall, Phoebe

426 Arrowsmith, Rachael Wain, Nadine Weeks, Rosie Holmes, William McCaig, Jessica Miller,

427 Sachin Prabhu, Rebecca Longmate, Sarah Cooper, Paul Stonelake, Maria Crowley, Islam

428 Abdo, Lawrence Wilson, Peter Bamford, Mike Protopapas, Alex Trimmings, Daniel Lutman,

429 Sanjiv Sharma, Dalijit Hothi, Deborah Lees, Anne MacNiven, Bridget Leavey, Ciara

430 McMullin, Dagmar Gohil, Syed Husain, Hozefa Ebrahim, Anil Kambli, Daniel Moult, Maria

431 Mcrittenden, Jane Sansom, Paul Hayden, Susannah Johnson, Akuratiyage Desilva, Nichola

432 White, Sarah Hare, Helen Langrick, Richard Lowsby, Julie Love, Jonathan Phillips, Geradine

433 Hardisty, Jagtar Pooni, Gordon French, Tristan McGeorge, Upeka Ranasinghe, Abdul Nazar,

434 George Collins, Fay Gilder, Rajnish Saha, Sara Blakeley, Catherine Snelson, Meriden

435 Cabales, Deidre McFarlane, Janet Lippett, Paul Dean, Amy Scott, Surrah Leifer, Stephen

436 Krueper, Sandra Barrington, Geeta Aggarwal, Ravi Kumar, Jane Dickson, Edward Cetti,

437 Carole Love, Chris Beevers, Abhijoy Chakladar, Caroline Dean, Dominique Melville, James

438 Nicholson, Aditya Kuravi, Karen Rawlings, Catherine Dexter, Allen Hornby, Andy Higgs,

439 Tim Furniss, Lisa Radley, Laura Langton, Andrew Badacsonyi, Mark Snazelle, Jane Kirk-

440 Smith, Julia Cristall, Karl Woods, Jane Unwin, Anna Dennis, Lisa Millin, Debbie Turner,

441 Nitin Arora, Nick Sherwood, Jonathan Hulme, Rebecca O'Dwyer, Omer Lodi, Ned Hobbs,

442 Manjeet Shehmar, Richard Stewart, Ganesh Suntharalingam, Carol Galvin, Tim Cook, Fiona

443 Kelly, Marghanita Jenkins, Debbie Van Der Velden, Thomas Best, Luis Colorado, Andre

444 Vercueil, Chris Langrish, Elaine Thorpe, Mark Paul, Nick McCartney, Noor Mohammed,

445 James Holding, Shameer Gopal, Jamie Smart, Prabhahar Thaventhran, Richard Breeze, Chris

446 Woolard, Jeremy Wilson, Sinead Hanton, Sean Carroll, Nicholas Barrett, Victoria

447 McCormack, Roopa McCrossan 
medRxiv preprint doi: https://doi.org/10.1101/2022.01.13.22269151; this version posted January 13, 2022. The copyright holder for this preprint (which was not certified by peer review) is the author/funder, who has granted medRxiv a license to display the preprint in perpetuity.

It is made available under a CC-BY-ND 4.0 International license .

448

449

\section{Declaration of Interests}

N.G. runs a consultancy which provides the NHS with active listening and peer support training. KF works at UCLH as a consultant anaesthetist, holds an academic chair at UCL, and is seconded to NHS England as an advisor. HWWP has received funding from Public Health England and from NHS England. HWWP has a PhD student who works at and has fees paid by AstraZeneca. KK works for the Care Quality Commission.

\section{Author Contributions}

CEH: Performed data analysis, drafted the manuscript, constructed all tables, designed all figures and prepared the manuscript for submission. JM: Study coordinator, developed protocol, supported data analysis, contributed to article revisions. CS: Contributed to protocol, supported data analysis, and contributed to article revisions. JKB: Contributed to protocol, contributed to write-up and article revisions. DW: Provided feedback on protocol and article revisions. HWWP: Supported and guided data analysis, commented on multiple versions of the draft manuscript. TC: Designed the electronic survey tools, supported data analysis and contributed to article revisions. MT: Assisted with recruitment and data collection, contributed to study design and article revisions. KK: Assisted with recruitment and data collection, contributed to study design and article revisions. SES: Assisted with recruitment and data collection, contributed to study design and article revisions. KF: Initiated the concept and formulated the initial design of the study and was a senior advisor to the project. NG: Led study design, study deployment and study team, contributed to serial article revisions. All authors have commented earlier versions of the manuscript and read and approved the final version of the manuscript.

\section{Data Sharing}

The data used within this study are not publicly available. 
medRxiv preprint doi: https://doi.org/10.1101/2022.01.13.22269151; this version posted January 13, 2022. The copyright holder for this preprint (which was not certified by peer review) is the author/funder, who has granted medRxiv a license to display the preprint in perpetuity.

It is made available under a CC-BY-ND 4.0 International license .

478 1. Aknin L, De Neve J-E, Dunn E, et al. A review and response to the early mental health and neurological consequences of the COVID-19 pandemic. 2021.

480 2. Wilson W, Raj JP, Rao S, et al. Prevalence and predictors of stress, anxiety, and

3. Al-Humadi S, Bronson B, Muhlrad S, et al. Depression, suicidal thoughts, and

6. Wanigasooriya K, Palimar P, Naumann DN, et al. Mental health symptoms in a

8. Greenberg N, Weston D, Hall C, et al. Mental health of staff working in intensive care

4. De Kock JH, Latham HA, Leslie SJ, et al. A rapid review of the impact of COVID-19 on the mental health of healthcare workers: implications for supporting psychological well-being. BMC Public Health. 2021;21(1):1-18.

5. Sahebi A, Nejati B, Moayedi S, et al. The prevalence of anxiety and depression among healthcare workers during the COVID-19 pandemic: An umbrella review of meta-analyses. Progress in Neuro-Psychopharmacology Biological Psychiatry. 2021:110247. cohort of hospital healthcare workers following the first peak of the COVID-19 pandemic in the UK. BJPsych open. 2021;7(1).

7. Yamamoto T, Uchiumi C, Suzuki N, Yoshimoto J, Murillo-Rodriguez E. The psychological impact of 'mild lockdown' in Japan during the COVID-19 pandemic: a nationwide survey under a declared state of emergency. International journal of environmental research public health. 2020;17(24):9382. during COVID-19. Occupational Medicine. 2021;71(2):62-7.

9. Greenberg N, Docherty M, Gnanapragasam S, Wessely S. Managing mental health challenges faced by healthcare workers during covid-19 pandemic. BMJ. 2020;368.

10. Roberts T, Daniels J, Hulme W, et al. COVID-19 emergency response assessment study: a prospective longitudinal survey of frontline doctors in the UK and Ireland: study protocol. BMJ open. 2020;10(8):e039851. 
medRxiv preprint doi: https://doi.org/10.1101/2022.01.13.22269151; this version posted January 13, 2022. The copyright holder for this preprint (which was not certified by peer review) is the author/funder, who has granted medRxiv a license to display the preprint in perpetuity.

It is made available under a CC-BY-ND 4.0 International license .

508 11. Salyers MP, Bonfils KA, Luther L, et al. The relationship between professional

509

510

511

512

513

514

515

516

517

518

519

520

521

522

523

524

525

526

527

528

529

530

531

532

533

534

535

536

537

538

539

540

541 burnout and quality and safety in healthcare: a meta-analysis. Journal of general internal medicine. 2017;32(4):475-82.

12. Tawfik DS, Scheid A, Profit J, et al. Evidence relating health care provider burnout and quality of care: a systematic review and meta-analysis. Annals of internal medicine. 2019;171(8):555-67.

13. Dolev T, Zubedat S, Brand Z, et al. Physiological parameters of mental health predict the emergence of post-traumatic stress symptoms in physicians treating COVID-19 patients. Translational psychiatry. 2021;11(1):1-9.

14. Mundt JC, Marks IM, Shear MK, Greist JM. The Work and Social Adjustment Scale: a simple measure of impairment in functioning. The British Journal of Psychiatry. 2002;180(5):461-4.

15. Fear NT, Seddon R, Jones N, Greenberg N, Wessely S. Does anonymity increase the reporting of mental health symptoms? 2012;12(1):1-7.

16. Wilson ALG, Hoge CW, McGurk D, et al. Application of a new method for linking anonymous survey data in a population of soldiers returning from Iraq. 2010;20(12):931-8.

17. Kroenke K, Spitzer RL, Williams JB. The PHQ $\square$ 9: validity of a brief depression severity measure. Journal of general internal medicine. 2001;16(9):606-13.

18. Lang AJ, Stein MB. An abbreviated PTSD checklist for use as a screening instrument in primary care. Behaviour research therapy. 2005;43(5):585-94.

19. Bush K, Kivlahan DR, McDonell MB, et al. The AUDIT alcohol consumption questions (AUDIT-C): an effective brief screening test for problem drinking. 1998;158(16):1789-95.

20. Spitzer RL, Kroenke K, Williams JB, Löwe B. A brief measure for assessing generalized anxiety disorder: the GAD-7. Archives of internal medicine. 2006;166(10):1092-7.

21. Smith LE, Michie S, Fear NT, Potts H, Rubin J, Amlôt R. Psychological wellbeing in the English population during the COVID-19 pandemic: a series of cross-sectional surveys. 2021.

22. Fancourt D, Bu F, Mak H, Paul E, Steptoe A. Covid-19 Social Study Results Release 32. London: University College London. Health DoBS. 2021.

23. Stevelink SA, Jones M, Hull Let al. Mental health outcomes at the end of the British involvement in the Iraq and Afghanistan conflicts: a cohort study. 2018;213(6):690-7. 
medRxiv preprint doi: https://doi.org/10.1101/2022.01.13.22269151; this version posted January 13, 2022. The copyright holder for this preprint (which was not certified by peer review) is the author/funder, who has granted medRxiv a license to display the preprint in perpetuity.

It is made available under a CC-BY-ND 4.0 International license .

542 24. Office of National Statistics. Coronavirus and depression in adults, Great Britain:

543

544

545

546

547

548

549

550

551

552

553

554

555

556

557

558

559

560

561

562

563

564

565

566

567

568

569

570

571

572

573

574 January to March 2021. 2021.

25. Daly M, Robinson E. Longitudinal changes in psychological distress in the UK from 2019 to September 2020 during the COVID-19 pandemic: Evidence from a large nationally representative study. Psychiatry Research. 2021;300:113920.

26. Dickerson J, Kelly B, Lockyer B, et al. 'When will this end? Will it end?'The impact of the March-June 2020 UK Covid-19 lockdown response on mental health: a longitudinal survey of mothers in the Born in Bradford study. medRxiv. 2020.

27. Moitra M, Rahman M, Collins PY, et al. Mental health consequences for healthcare workers during the COVID-19 pandemic: a scoping review to draw lessons for LMICs. Frontiers in psychiatry. 2021;12:22.

28. Kisely S, Warren N, McMahon L, et al. Occurrence, prevention, and management of the psychological effects of emerging virus outbreaks on healthcare workers: rapid review and meta-analysis. BMJ. 2020;369.

29. Lamb D, Gnanapragasam S, Greenberg N, et al. The psychosocial impact of COVID19 pandemic on 4,378 UK healthcare workers and ancillary staff: initial baseline data from a cohort study collected during the first wave of the pandemic. medRxiv preprint server. 2021.

30. Fear NT, Rubin GJ, Hatch S, et al. Job strain, rank, and mental health in the UK Armed Forces. 2009;15(3):291-8.

31. Boullier M, Blair MJP, Health C. Adverse childhood experiences. 2018;28(3):132-7.

32. Garrouste-Orgeas M, Perrin M, Soufir L, et al. The Iatroref study: medical errors are associated with symptoms of depression in ICU staff but not burnout or safety culture. 2015;41(2):273-84.

33. Tracy DK, Tarn M, Eldridge R, et al. What should be done to support the mental health of healthcare staff treating COVID-19 patients? The British Journal of Psychiatry. 2020;217(4):537-9.

34. Chirico F, Nucera G, Magnavita N. Protecting the mental health of healthcare workers during the COVID-19 emergency. BJPsych International. 2021;18(1).

35. Ward RN, Carlson KJ, Erickson AJ, Yalch MM, Brown LM. Associations of humor, morale, and unit cohesion on posttraumatic stress disorder symptoms. 2021:1-10.

36. De Simone S, Vargas M, Servillo G. Organizational strategies to reduce physician burnout: a systematic review and meta-analysis. 2021;33(4):883-94. 
medRxiv preprint doi: https://doi.org/10.1101/2022.01.13.22269151; this version posted January 13, 2022. The copyright holder for this preprint (which was not certified by peer review) is the author/funder, who has granted medRxiv a license to display the preprint in perpetuity. It is made available under a CC-BY-ND 4.0 International license.

575 37. Akhanemhe R, Wallbank S, Greenberg N. An evaluation of REACTMH mental

576 health training for healthcare supervisors. J Occupational Medicine. 2021;71(3):127-

577 30. 
medRxiv preprint doi: https://doi.org/10.1101/2022.01.13.22269151; this version posted January 13, 2022. The copyright holder for this preprint (which was not certified by peer review) is the author/funder, who has granted medRxiv a license to display the preprint in perpetuity. It is made available under a CC-BY-ND 4.0 International license.

600 Table 1

601 ICU Participant characteristics.

\begin{tabular}{|c|c|c|c|}
\hline Variables & $\begin{array}{c}\text { Before the surge } \\
\qquad \begin{array}{c}(\boldsymbol{n}=\mathbf{8 0 9}) \\
n(\%)\end{array}\end{array}$ & $\begin{array}{l}\text { During the surge } \\
\qquad \begin{array}{c}(\boldsymbol{n}=2792) \\
n(\%)\end{array}\end{array}$ & $\begin{array}{l}\text { After the surge } \\
\qquad \begin{array}{c}(n=2479) \\
n(\%)\end{array}\end{array}$ \\
\hline \multicolumn{4}{|l|}{ Gender } \\
\hline Male & $266(32.9)$ & $719(25.8)$ & 667 (26.9) \\
\hline Female & $536(66.3)$ & $2053(73.5)$ & $1790(72.2)$ \\
\hline Other $^{a}$ & $7(0.9)$ & $20(0.7)$ & $22(0.9)$ \\
\hline \multicolumn{4}{|l|}{ Age } \\
\hline $16-29$ & $141(17.4)$ & $550(19.7)$ & $426(17.2)$ \\
\hline $30-44$ & $374(46.2)$ & $1320(47.3)$ & $1216(49.1)$ \\
\hline $45-56$ & $268(33.1)$ & 849 (30.4) & $756(30.5)$ \\
\hline $60+$ & $26(3.2)$ & $73(2.6)$ & $81(3.3)$ \\
\hline \multicolumn{4}{|l|}{ Role } \\
\hline Doctor & $258(31.9)$ & $791(28.3)$ & 649 (26.2) \\
\hline \multicolumn{4}{|l|}{ Type } \\
\hline Anaesthesia & 157 (60.9) & $401(50.7)$ & $322(49.6)$ \\
\hline$I C U$ & $89(34.5)$ & $317(40.1)$ & $280(43.1)$ \\
\hline Other & $12(4.7)$ & $73(9.2)$ & $47(7.2)$ \\
\hline \multicolumn{4}{|l|}{ Grade } \\
\hline Junior $^{b}$ & $93(36.0)$ & $300(37.9)$ & $197(30.4)$ \\
\hline Senior ${ }^{c}$ & $165(64.0)$ & $491(62.1)$ & $452(69.6)$ \\
\hline Nurse & $428(52.9)$ & $1615(57.8)$ & 1455 (58.7) \\
\hline \multicolumn{4}{|l|}{ Type } \\
\hline$I C U$ & $351(82)$ & $1334(82.6)$ & $1260(86.6)$ \\
\hline Other & $16(3.7)$ & $171(10.6)$ & 115 (7.9) \\
\hline Theatres & $61(14.3)$ & $110(6.8)$ & $80(5.5)$ \\
\hline \multicolumn{4}{|l|}{ Grade } \\
\hline Junior $^{d}$ & $329(76.9)$ & $1264(78.3)$ & $1113(76.5)$ \\
\hline Senior ${ }^{e}$ & $99(23.1)$ & $351(21.7)$ & $342(23.5)$ \\
\hline
\end{tabular}


medRxiv preprint doi: https://doi.org/10.1101/2022.01.13.22269151; this version posted January 13, 2022. The copyright holder for this preprint (which was not certified by peer review) is the author/funder, who has granted medRxiv a license to display the preprint in perpetuity. It is made available under a CC-BY-ND 4.0 International license.

Other $^{\mathrm{f}}$

$386(13.8)$

$375(15.1)$

602 Note: ${ }^{a}$ : indicates both, those who chose to not disclose their gender, and those who selected

603 'other'. '. refers to those who chose the following grading categories: FY 1-2, ST 3-4, ST 5-6,

604 ST 6-7. ${ }^{\text {c }}$ : refers to those who chose the following grading categories: consultant or senior

605 associate specialist. ${ }^{\mathrm{d}}$ : refers to those who chose the following grading categories: Band 5 or

606 Band 6. ${ }^{\text {e}}$ : refers to those who chose the following grading categories Band 7, Band 8 or Band

607 9. ${ }^{\mathrm{f}}$ : encompasses the following job roles: Healthcare assistant, Occupational therapist,

608 Operating Department Practitioner (ODP), Pharmacist, Physiotherapist and 'Other'.

609

610

611

612

613

614

615

616

617

618

619

620

621

622

623

624

625

626

627

628 
medRxiv preprint doi: https://doi.org/10.1101/2022.01.13.22269151; this version posted January 13, 2022. The copyright holder for this preprint (which was not certified by peer review) is the author/funder, who has granted medRxiv a license to display the preprint in perpetuity. It is made available under a CC-BY-ND 4.0 International license.

629 Figure 1

630 CONSORT 2020 Participant Flow Diagram

631

632

633

634

CONSORT 2010 Flow Diagram

${ }_{636}^{635}$

637

638

639

640

641

642

643

644

\section{Enrollment}
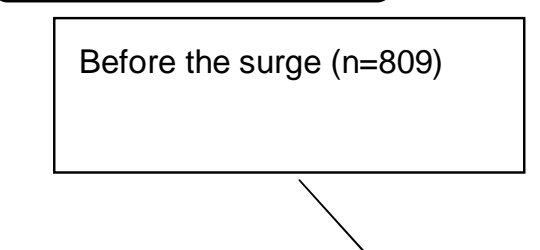

During the surge $(n=2792)$

After the surge $(n=2479)$

645

646

647

\section{Analysis}

648

Analysed $(n=6080)$

- Excluded from analysis $(n=0)$

649

Excluded $(n=0)$

650

651

652 
medRxiv preprint doi: https://doi.org/10.1101/2022.01.13.22269151; this version posted January 13, 2022. The copyright holder for this preprint (which was not certified by peer review) is the author/funder, who has granted medRxiv a license to display the preprint in perpetuity. It is made available under a CC-BY-ND 4.0 International license .

\section{$654 \quad$ Figure 2}

655 Percentage prevalence and confidence intervals of participants meeting the threshold criteria

656 for depression, anxiety, PTSD and problem drinking across the COVID-19 2020/2021 winter

657 surge.

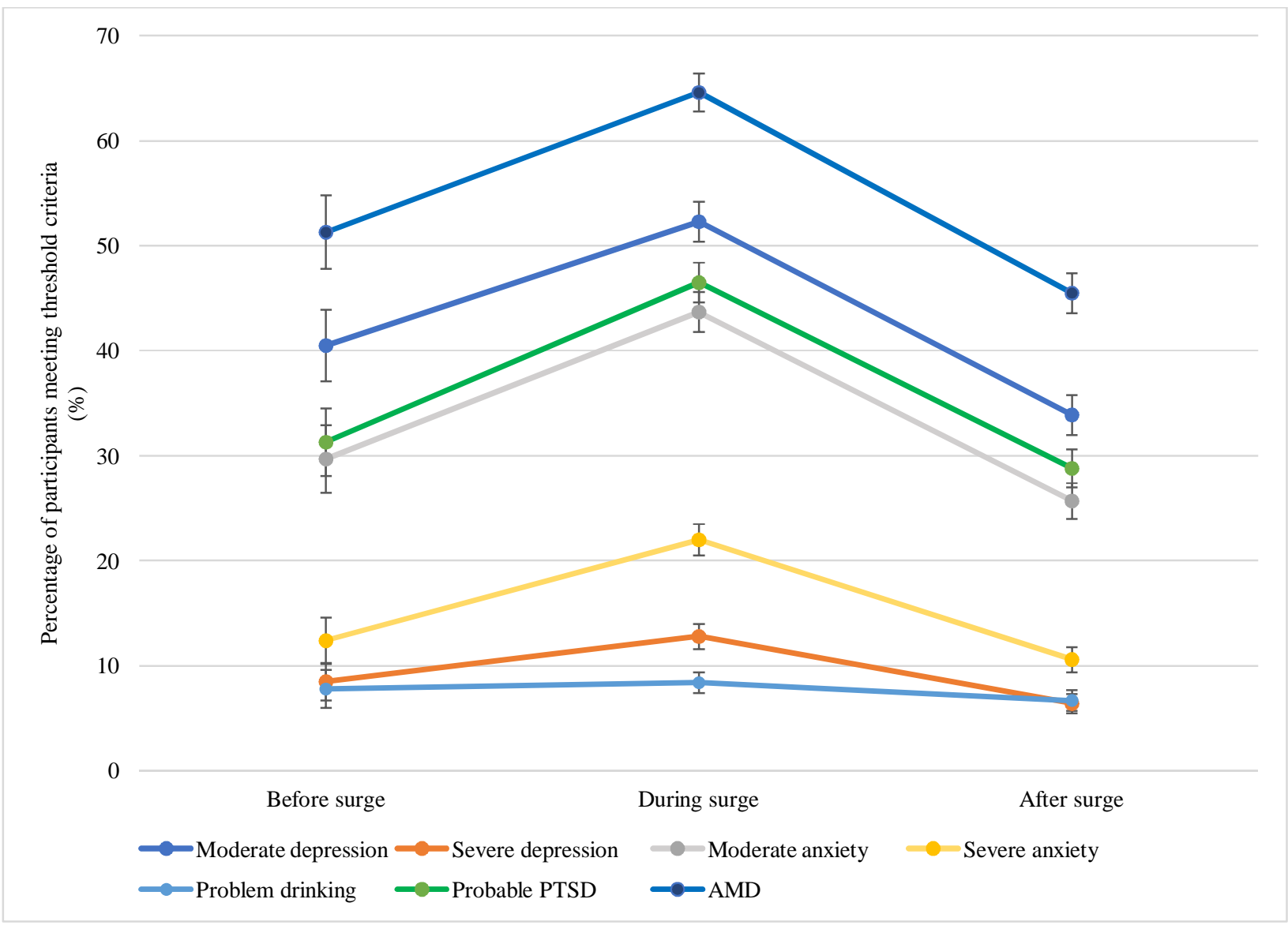

659 Note. Before, after and during samples are independent. The joining lines act as a visual aid. 660 Before surge represents 19th November to 17th December 2020; during the surge represents 661 26th January - 17th February 2021; and after the surge represents - 14th April - 24th May 6622021. 
$669 \quad$ Figure 3

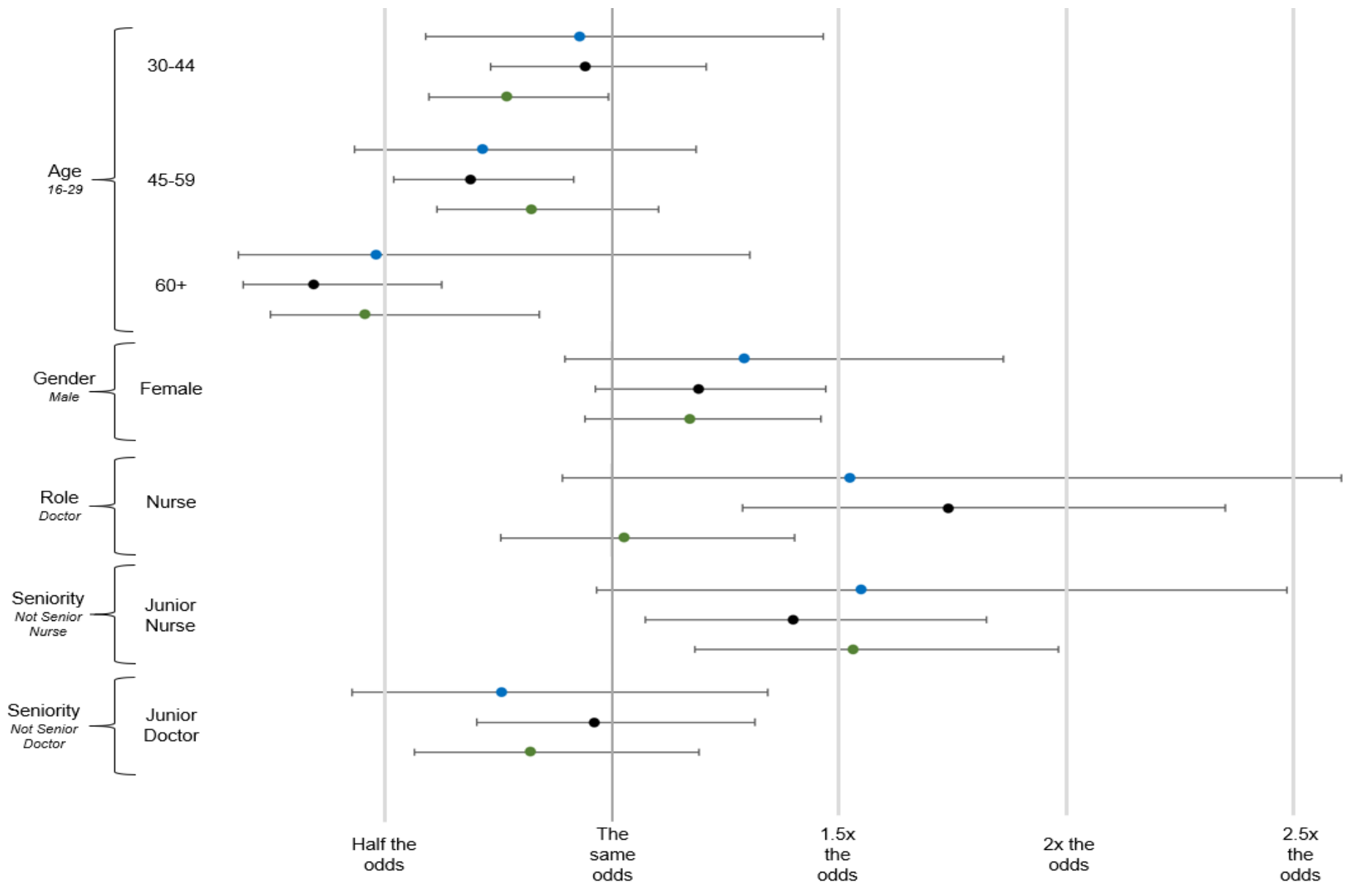


672 Note: Blue markers indicate before the surge, black markers indicate during the surge, and green markers indicates after the surge. Reference 673 group italicised under each variable. Analysis was only carried out for doctors and nurses, senior nurses were compared to all others 674 (junior nurses and all doctors); senior doctors were compared to all others (junior doctors and all nurses). 
$675 \quad$ Figure 4

676 Forest plot displaying confidence intervals and effect sizes for each variable's effect on functional impairment over each timepoint.

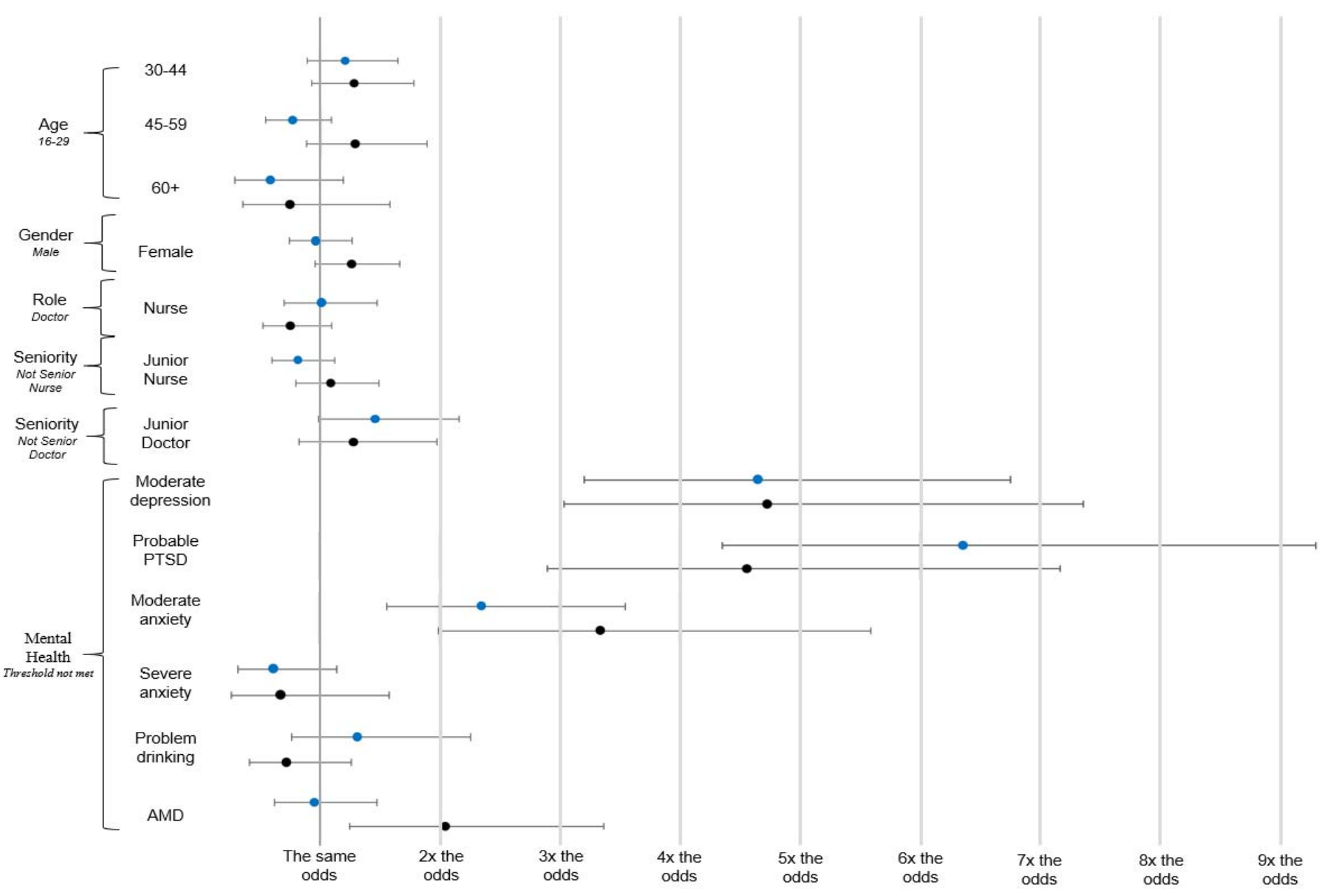


678 Note: Reference group italicised under each variable. Analysis was only carried out for doctors and nurses, senior nurses were compared to all 679 others (junior nurses and all doctors); senior doctors were compared to all others (junior doctors and all nurses). 